\title{
A computational study of nitramide adsorption on the electrical properties of pristine and C-replaced boron nitride nanosheet
}

\author{
Mahdi Rezaei-Sameti ${ }^{1} \cdot$ Neda Javadi Jukar ${ }^{1}$
}

Received: 4 May 2017/Accepted: 26 July 2017/Published online: 5 August 2017

(C) The Author(s) 2017. This article is an open access publication

\begin{abstract}
The aims of this work is to scrutinize the structural, physical and electrical properties of nitroamine $\left(\mathrm{NH}_{2} \mathrm{NO}_{2}\right)$ adsorption on the outer and inner surface of pristine and C-replacing boron nitride nanosheet (BN nanosheet), using density functional theory methods at cam-B3LYP/6-31G (d) level of theory. Inspections of determined results represent that the adsorption of nitramide on the outer surface of pristine and C-replaced BN nanosheet is exothermic and on the inner surface it is endothermic. The deformation energy of system displays that the geometry and structure of $\mathrm{BN}$ nanosheet and nitramide in the $\mathrm{BN}$ nanosheet/ $\mathrm{NH}_{2} \mathrm{NO}_{2}$ complex change significantly from the original state, whereas the quantum parameters and gap energy of the $\mathrm{BN}$ nanosheet $/ \mathrm{NH}_{2} \mathrm{NO}_{2}$ system alter slightly from the original state. The nuclear magnetic resonance and molecular electrostatic potential consequences exhibit that in the $\mathrm{BN}$ nanosheet $/ \mathrm{NH}_{2} \mathrm{NO}_{2}$ complex, the highest density of electrons is concentrated surrounding the $\mathrm{NH}_{2} \mathrm{NO}_{2}$ molecule.
\end{abstract}

Keywords Boron nitride nanosheet $\cdot \mathrm{C}$ replaced $\cdot \mathrm{NH}_{2} \mathrm{NO}_{2}$ adsorption $\cdot$ Density functional theory $\cdot$ Molecular electrostatic potential

Electronic supplementary material The online version of this article (doi:10.1007/s40097-017-0237-2) contains supplementary material, which is available to authorized users.

Mahdi Rezaei-Sameti

mrsameti@gmail.com; mrsameti@malayeru.ac.ir

1 Department of Applied Chemistry, Faculty of Science, Malayer University, Malayer 65174, Iran

\section{Introduction}

After the discovery of the carbon nanotube, extensive researches have been done to find other nanomaterials and nanoconfigurations. One of the most interesting configurations of carbon is graphene. It is a crystalline allotrope of carbon with two-dimensional properties. Due to its fascinating structural and electronic properties, it is suitable for providing electronic nanosheets or nanosensors [1-7]. The band gap of graphene sheet is almost zero and this property is useful to making electronic devices. In recent years, functionalizing and doping methods have been extensively used to increase the efficiency of graphene sheet in electronic and nanodetector applications [8-11]. In recent years, many researches have focused on finding other nanosheet compounds such as silicon carbide, boron phosphide, aluminum nitride, zinc oxide, gallium nitride, aluminum phosphide, beryllium oxide and boron nitride [12-18]. Boron nitride nanosheet was discovered in 2005 and, due to its structural and fundamental properties, it is useful in making nanochips, nanosensors, optoelectronic devices, nanoscale device technology and nanoadsorbent [19-30]. On the other hand, $\mathrm{BN}$ nanosheet with a band gap in the range of $4.2-6 \mathrm{eV}$ is notably used to make a sensitive sensor of toxic and hazardous compounds in industries [12, 27, 28, 31-35].

Nitroamine $\left(\mathrm{NH}_{2} \mathrm{NO}_{2}\right)$ is the simplest nitramine compound that is greatly used in military explosive, propellant and fuel applications. In recent years, extensive theoretical and experimental investigations have been done on the interaction of $\mathrm{NH}_{2} \mathrm{NO}_{2}$ compound with nanomaterials and nanotubes $[36,37]$. In the current work, the structural, physical, and electrical properties of $\mathrm{BN}$ nanosheet in the presence of C-replaced and $\mathrm{NH}_{2} \mathrm{NO}_{2}$ molecule were studied using the DFT theory. To find the appropriate and suitable adsorption sites, many different configurations and orientations of 
$\mathrm{NH}_{2} \mathrm{NO}_{2}$ molecule on the $\mathrm{B}$ and $\mathrm{N}$ sites of nanosheet were examined, and all configuration models were optimized using B3LYP/3-21G level of theory. From all optimized models, the ten (10) stable and suitable models were selected for this work and then the selected models were optimized again using camB3LYP/6-31G (d) level of theory. The geometrical, chemical reactivity, quantum parameters, adsorption, deformation energy, and molecular electrostatic potential for all selected models are determined and analyzed. The obtained results may be useful for performing an adsorbent or nanosensor for detecting nitramine molecule.

\section{Computational section}

For denoting the adsorption of $\mathrm{NH}_{2} \mathrm{NO}_{2}$ molecule on the surface of pristine and $\mathrm{C}$-replaced $\mathrm{BN}$ nanosheet, we define the $\mathrm{A}$ and $\mathrm{B}$ models, respectively. The a, b, c, $\mathrm{d}$ and $\mathrm{e}$ indexes are used for adsorption of $\mathrm{NH}_{2} \mathrm{NO}_{2}$ from $\mathrm{H}$, $\mathrm{N}\left(\mathrm{NH}_{2}\right), \mathrm{O}, \mathrm{N}\left(\mathrm{NO}_{2}\right)$ head and parallel orientation on the boron position of the $\mathrm{BN}$ nanosheet, respectively (see Fig. 1). The $f, g, h, i$ and $j$ indexes are used for adsorption of $\mathrm{NH}_{2} \mathrm{NO}_{2}$ molecule from $\mathrm{H}, \mathrm{N}\left(\mathrm{NH}_{2}\right), \mathrm{O}, \mathrm{N}\left(\mathrm{NO}_{2}\right)$ head and parallel orientation on the nitrogen position of the $\mathrm{BN}$ nanosheet, respectively.

The A-a to B-j models are optimized by using the DFT method at cam-B3LYP level of theory using the 6-31G (d) base set [38] when performing the GAMESS suite of programs [39]. The pristine and C-replaced BN nanosheet and the A-a to B-j models before and after the optimizing process are given in Figs. 1 and 2. The ends of the nanosheet at all systems are saturated by hydrogen atoms for preventing the dangling bonds at the edges of the nanosheet. The adsorption energy $\left(E_{\text {ads }}\right)$ [40-42] of $\mathrm{NH}_{2} \mathrm{NO}_{2}$ molecule on the surface of pristine, C-replaced $\mathrm{BN}$ nanosheet is calculated by:

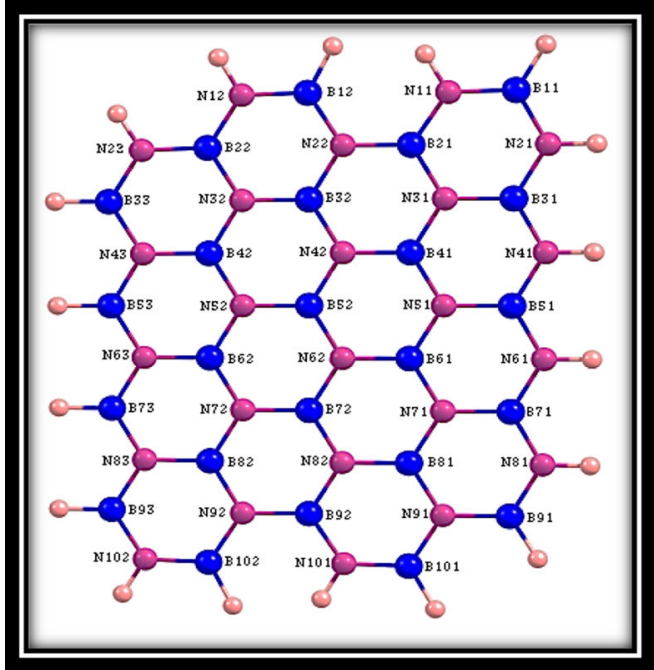

A

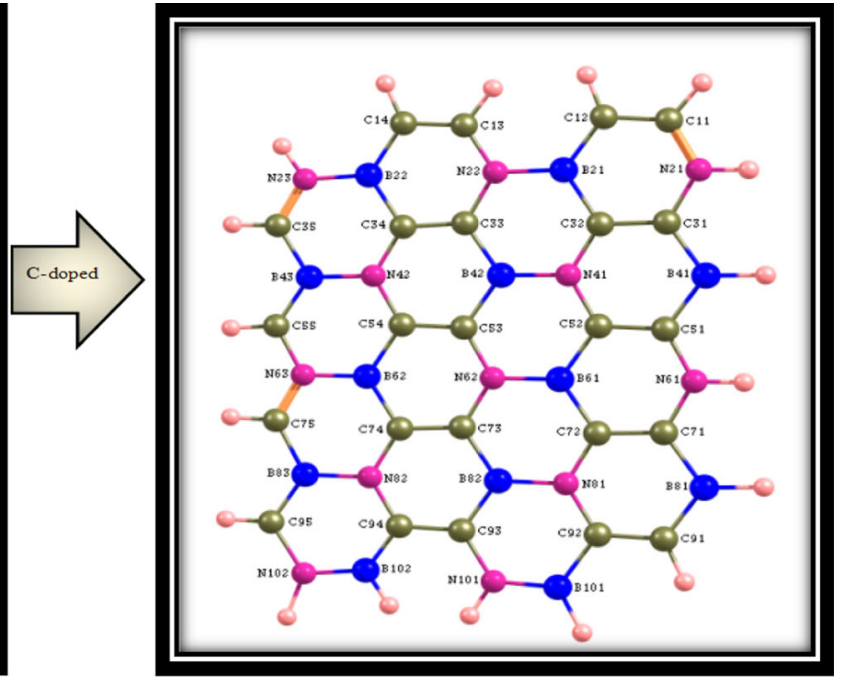

B

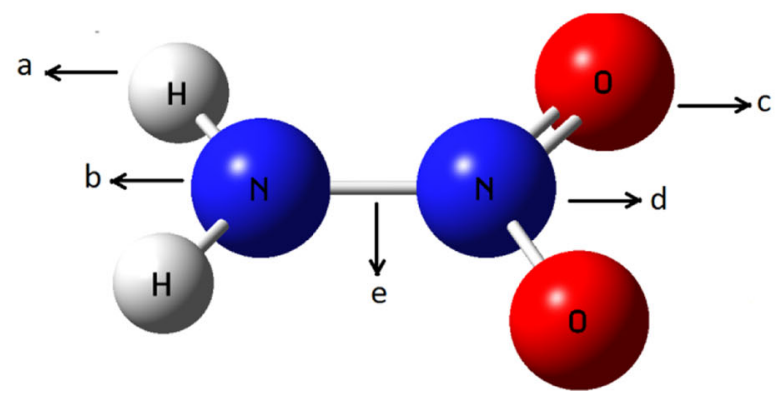

Fig. $12 \mathrm{D}$ views of the pristine and C-doped BN nanosheets 


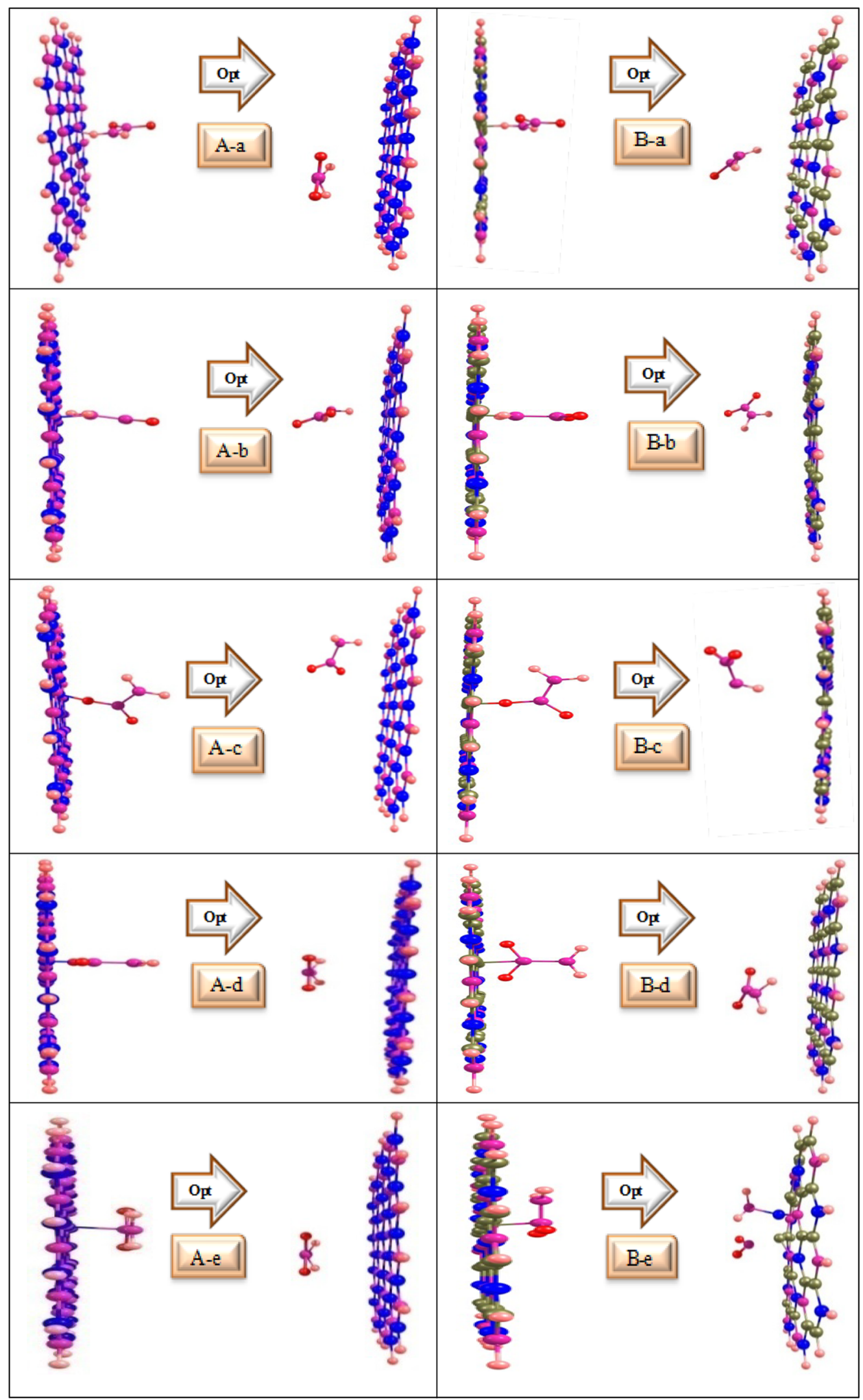

Fig. 2 2D views of $\mathrm{NH}_{2} \mathrm{NO}_{2}$ adsorption on the surface of pristine and C-doped $\mathrm{BN}$ nanosheets (A-a to B-j models); in all models the left configuration is before optimization 


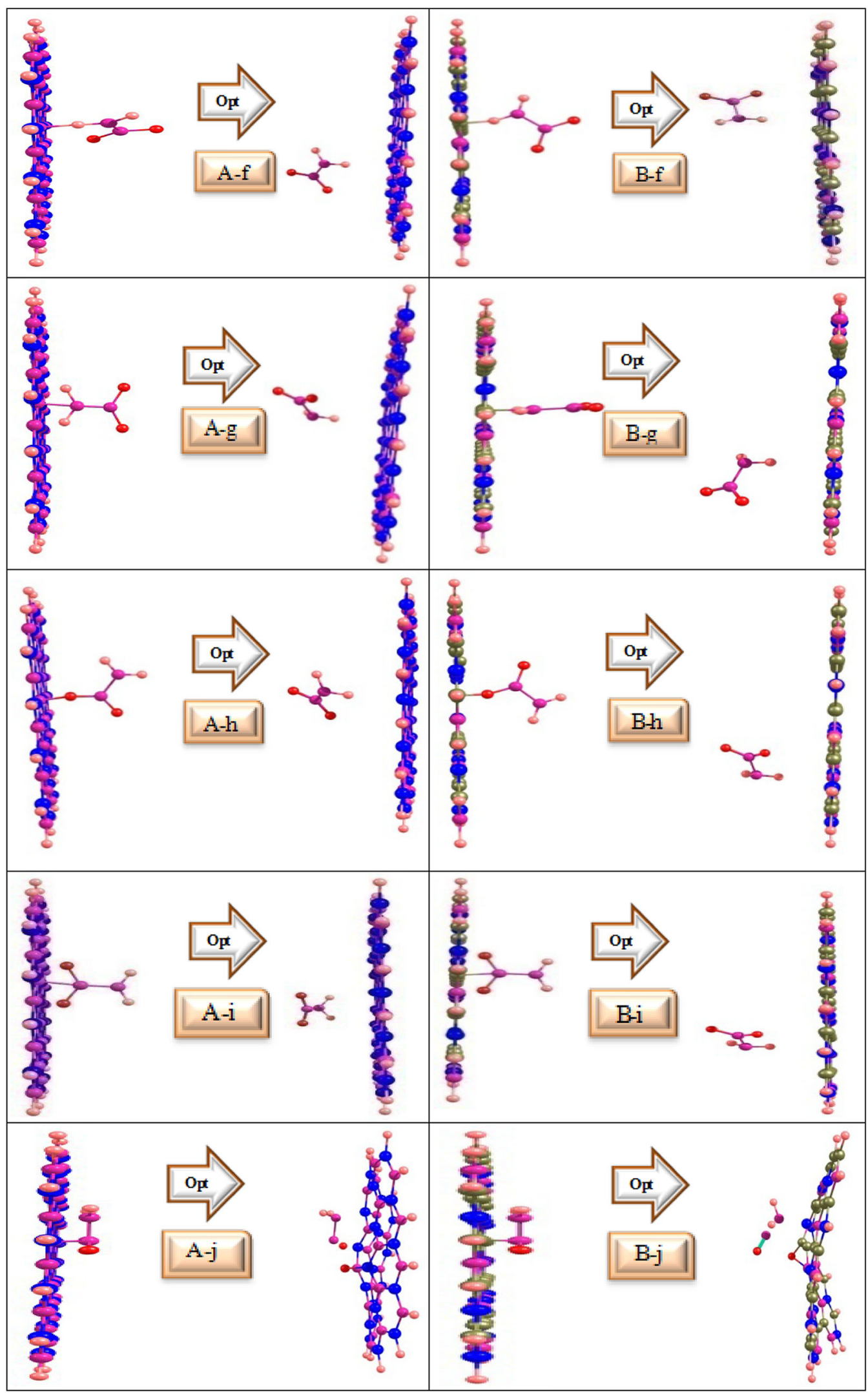

Fig. 2 continued 


$$
\begin{aligned}
E_{\text {ads }}= & E_{\mathrm{BN}-\text { nanosheet } / \mathrm{NH}_{2} \mathrm{NO}_{2}}-\left(E_{\mathrm{BN}-\text { nano sheet }}+E_{\mathrm{NH}_{2} \mathrm{NO}_{2}}\right) \\
& + \text { BSSE. }
\end{aligned}
$$

$E_{\mathrm{BN}-\text { nano sheet } / \mathrm{NH}_{2} \mathrm{NO}_{2}}, E_{\mathrm{BN}-\text { nano sheet }}$ and $E_{\mathrm{NH}_{2} \mathrm{NO}_{2}}$ are the total potential energy of the $\mathrm{BN}$ nanosheet/ $\mathrm{NH}_{2} \mathrm{NO}_{2}$ system, $\mathrm{BN}$ nanosheet and $\mathrm{NH}_{2} \mathrm{NO}_{2}$, respectively, and the BSSE is the base set superposition error. The deformation energy $\left(E_{\mathrm{def}}\right)$ of the $\mathrm{BN}$ nanosheet, $\mathrm{NH}_{2} \mathrm{NO}_{2}$ molecule, $\mathrm{BN}$ nanosheet/ $\mathrm{NH}_{2} \mathrm{NO}_{2}$ complex and binding energy $\left(E_{\mathrm{bin}}\right)$ for the A-a to B-j systems are calculated by Eqs. (2-5) [43].

$$
\begin{aligned}
& E_{\text {def BN-nanosheet }}= E_{\mathrm{BN}-\text { nanosheet pure }} \\
&-E_{\mathrm{BN}-\text { nanosheet in system }}, \\
& E_{\text {def-}-\mathrm{NH}_{2} \mathrm{NO}_{2}}=E_{\mathrm{NH}_{2} \mathrm{NO}_{2} \text { pure }}-E_{\mathrm{NH}_{2} \mathrm{NO}_{2} \text { in system },}
\end{aligned}
$$

where $E_{\mathrm{BN} \text {-nanosheet in system }}$ and $E_{\mathrm{NH}_{2} \mathrm{NO}_{2}}$ are the energy of the $\mathrm{BN}$ nanosheet and $\mathrm{NH}_{2} \mathrm{NO}_{2}$ molecule in the $\mathrm{BN}$ nanosheet $/ \mathrm{NH}_{2} \mathrm{NO}_{2}$ system, when $\mathrm{NH}_{2} \mathrm{NO}_{2}$ and $\mathrm{BN}$ nanosheet are absent, respectively:

$$
\begin{aligned}
E_{\mathrm{bin}}= & E_{\mathrm{BN}-\text { nanosheet } / \mathrm{NH}_{2} \mathrm{NO}_{2}-\left(E_{\mathrm{BN}-\text { nanosheet in system }}\right.} \\
& \left.+E_{\mathrm{NH}_{2} \mathrm{NO}_{2} \text { in system }}\right), \\
E_{\text {total def }}= & E_{\text {ads }}-E_{\text {bin }} .
\end{aligned}
$$

The $E_{\text {totaldef }}, E_{\text {defBN-nanosheet }}$ and $E_{\text {def } \mathrm{NH}_{2} \mathrm{NO}_{2}}$ are the deformation energy of the $\mathrm{BN}$ nanosheet/ $\mathrm{NH}_{2} \mathrm{NO}_{2}$ system, $\mathrm{BN}$ nanosheet and $\mathrm{NH}_{2} \mathrm{NO}_{2}$ molecule in their optimized structure.
The highest occupied molecular orbital (HOMO) and the lowest unoccupied molecular orbital (LUMO) energies are used for determining the gap energy $\left(E_{\mathrm{g}}\right)$, density of state (DOS) plots, Fermi level energy $\left(E_{\mathrm{FL}}\right)$ and work functions $(\Delta \varphi)$ (see Eqs. 6-8):

$E_{\text {gap }}=E_{\mathrm{LUMO}}-E_{\mathrm{HOMO}}$,

$E_{\mathrm{FL}}=\left(E_{\mathrm{HOMO}}+E_{\mathrm{LUMO}}\right) / 2$,

$\Delta \phi=E_{\mathrm{HOMO}}-E_{\mathrm{FL}}$.

The chemical potential $(\mu)$ and electronegativity of nanosheet $(\chi)$, global hardness $(\eta)$ and softness $(S)$ of nanosheet, index of electrophilicity $(\omega)$ and charge transfer parameters $(\Delta N)$ of the A-a to $\mathrm{B}-\mathrm{j}$ adsorption systems are calculated using Eqs. (9-14):

$\mu=-(I+A) / 2$,

$\chi=-\mu$,

$\eta=(I-A) / 2$,

$\omega=\mu^{2} / 2 \eta$,

$S=1 / 2 \eta$,

$\Delta N=(-\mu / \eta)$,

where $A=-E_{\mathrm{LUMO}}$ and $I=-E_{\mathrm{HOMO}}$ are the electron affinity and ionization potential, respectively [40-42].
Table 1 The adsorption energy, deformation energy, binding energy, $\left(\mathrm{Kcal} \mathrm{mol}^{-1}\right)$, distance between the $\mathrm{BN}$. nanosheet and $\mathrm{NH}_{2} \mathrm{NO}_{2}(\AA)$ and dipole moment of the $\mathrm{BN}$ nanosheet $/ \mathrm{NH}_{2} \mathrm{NO}_{2}$ (debye) for the A-a to B-j models

\begin{tabular}{lllllllc}
\hline Model & $E_{\text {ads }}$ & $E_{\text {def BN-nanosheet }}$ & $E_{\text {def } \mathrm{NH}_{2} \mathrm{NO}_{2}}$ & $E_{\text {bin }}$ & $E_{\text {def (total) }}$ & Distance & Dipole moment \\
\hline A-a & -6.85 & 0.29 & -1.75 & -5.39 & -1.46 & 3.20 & 2.14 \\
A-b & -6.24 & 0.38 & -1.74 & -4.88 & -1.36 & 3.28 & 2.71 \\
A-c & -6.85 & 0.35 & -1.75 & -5.46 & -1.39 & 3.29 & 5.96 \\
A-d & -6.90 & 0.24 & -1.76 & -5.38 & -1.52 & 3.47 & 2.12 \\
A-e & -5.42 & 0.98 & -1.55 & -4.85 & -0.57 & 3.62 & 2.17 \\
B-a & -8.56 & -0.70 & -1.55 & -6.31 & -2.25 & 3.53 & 9.29 \\
B-b & -8.94 & -0.68 & -1.54 & -6.71 & -2.23 & 3.40 & 7.78 \\
B-c & -8.38 & -0.60 & -1.53 & -6.23 & -2.15 & 3.69 & 12.38 \\
B-d & -8.54 & -0.72 & -1.50 & -6.31 & -2.23 & 3.45 & 10.12 \\
B-e & 16.47 & 73.60 & 116.10 & -173.22 & 189.69 & 1.51 & 13.84 \\
A-f & -5.16 & 1.06 & -1.57 & -4.66 & -0.50 & 3.39 & 2.66 \\
A-g & -5.18 & 1.10 & -1.57 & -4.71 & -0.47 & 3.38 & 6.33 \\
A-h & -5.84 & 1.09 & -1.56 & -5.38 & -0.46 & 3.34 & 5.97 \\
A-i & -5.84 & 0.77 & -1.51 & -5.10 & -0.74 & 3.65 & 3.07 \\
A-j & 135.97 & 163.25 & 186.95 & -214.22 & 350.19 & 1.77 & 12.55 \\
B-f & -9.12 & -0.67 & -1.55 & -6.89 & -2.23 & 3.39 & 7.96 \\
B-g & -10.48 & -0.74 & -1.42 & -8.31 & -2.17 & 3.46 & 6.30 \\
B-h & -8.72 & -0.77 & -1.51 & -6.44 & -2.28 & 3.59 & 9.17 \\
B-i & -8.79 & -0.75 & -1.50 & -6.53 & -2.26 & 3.60 & 8.83 \\
B-j & 26.76 & 107.44 & 171.19 & -251.87 & 278.63 & 1.63 & 13.50 \\
\hline & & & & & & &
\end{tabular}




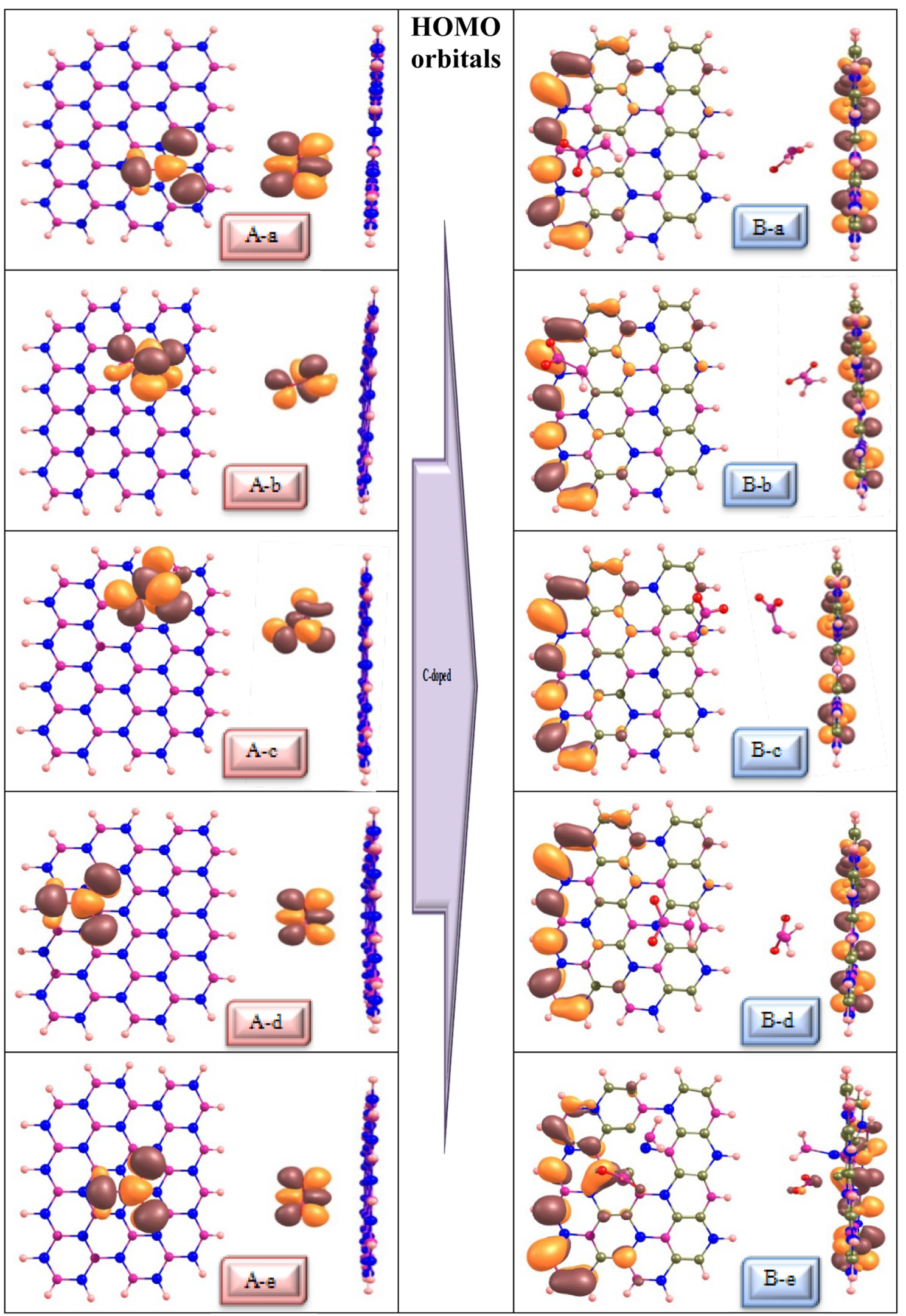

Fig. 3 Plots of HOMO and LUMO orbital structures for $\mathrm{NH}_{2} \mathrm{NO}_{2}$ adsorption on the surface of pristine and C-doped $\mathrm{BN}$ nanosheets $(\mathrm{A}$-a to $\mathrm{B}$ - $\mathrm{j}$ models, see Fig. 2) 


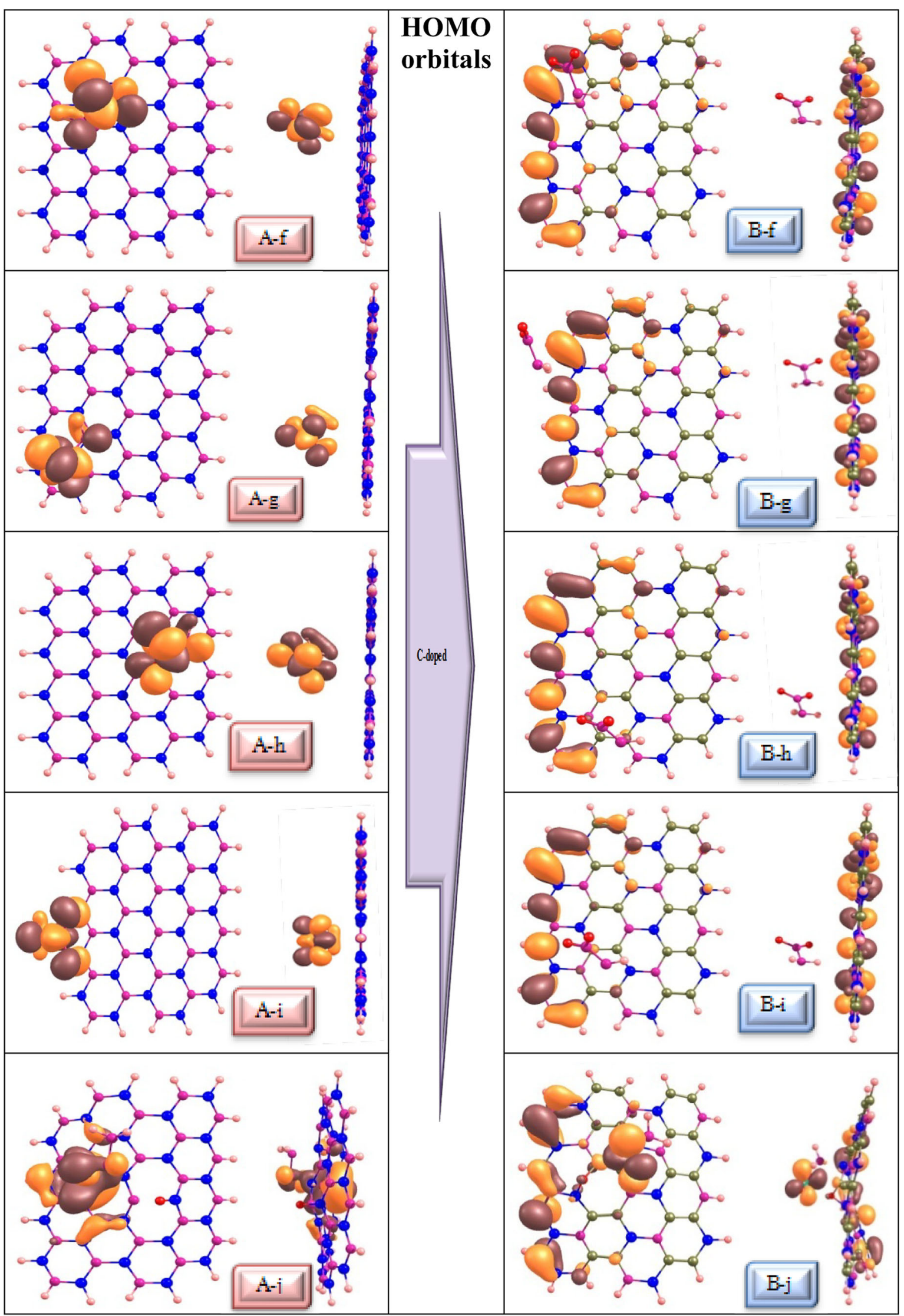

Fig. 3 continued 


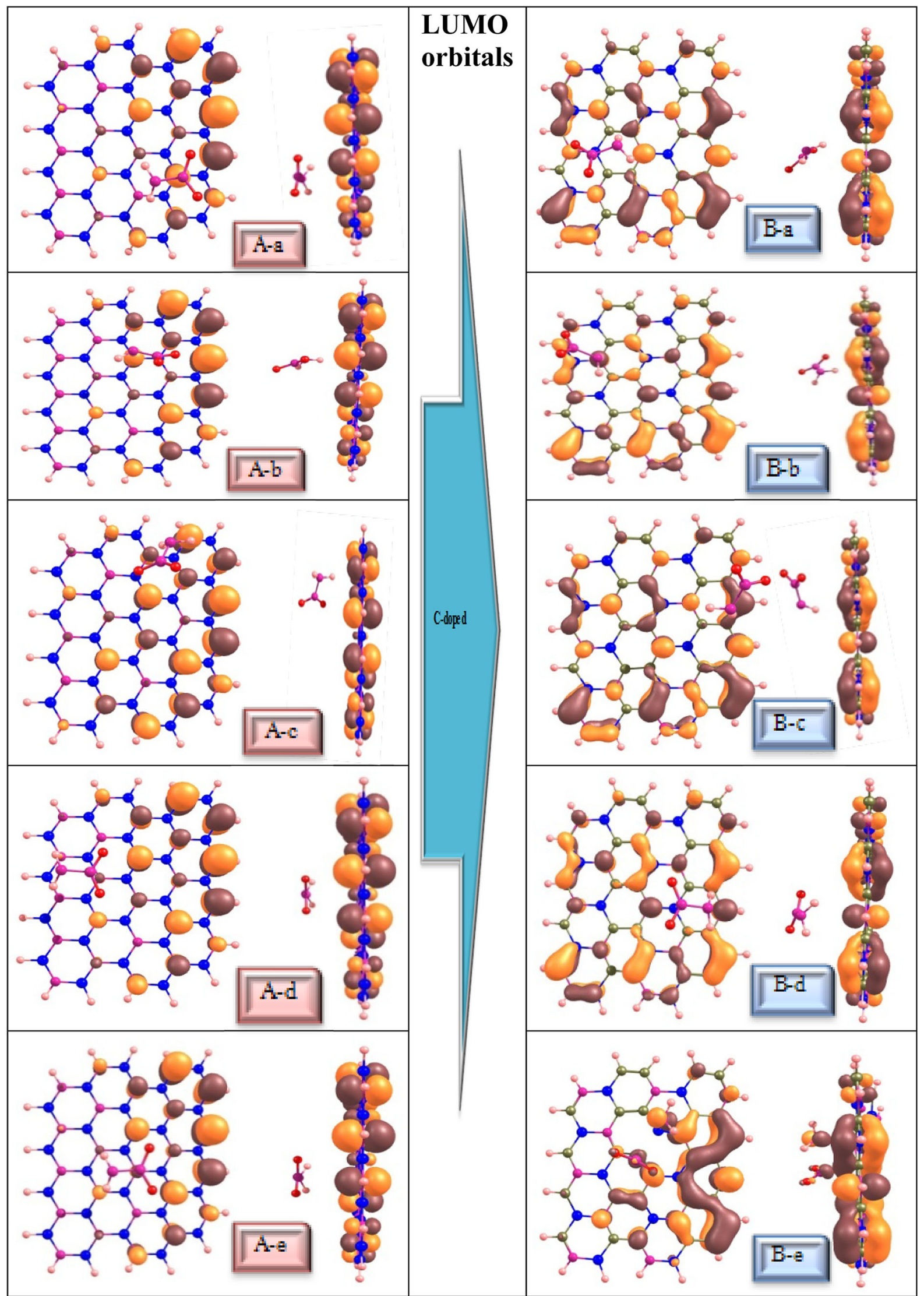

Fig. 3 continued 


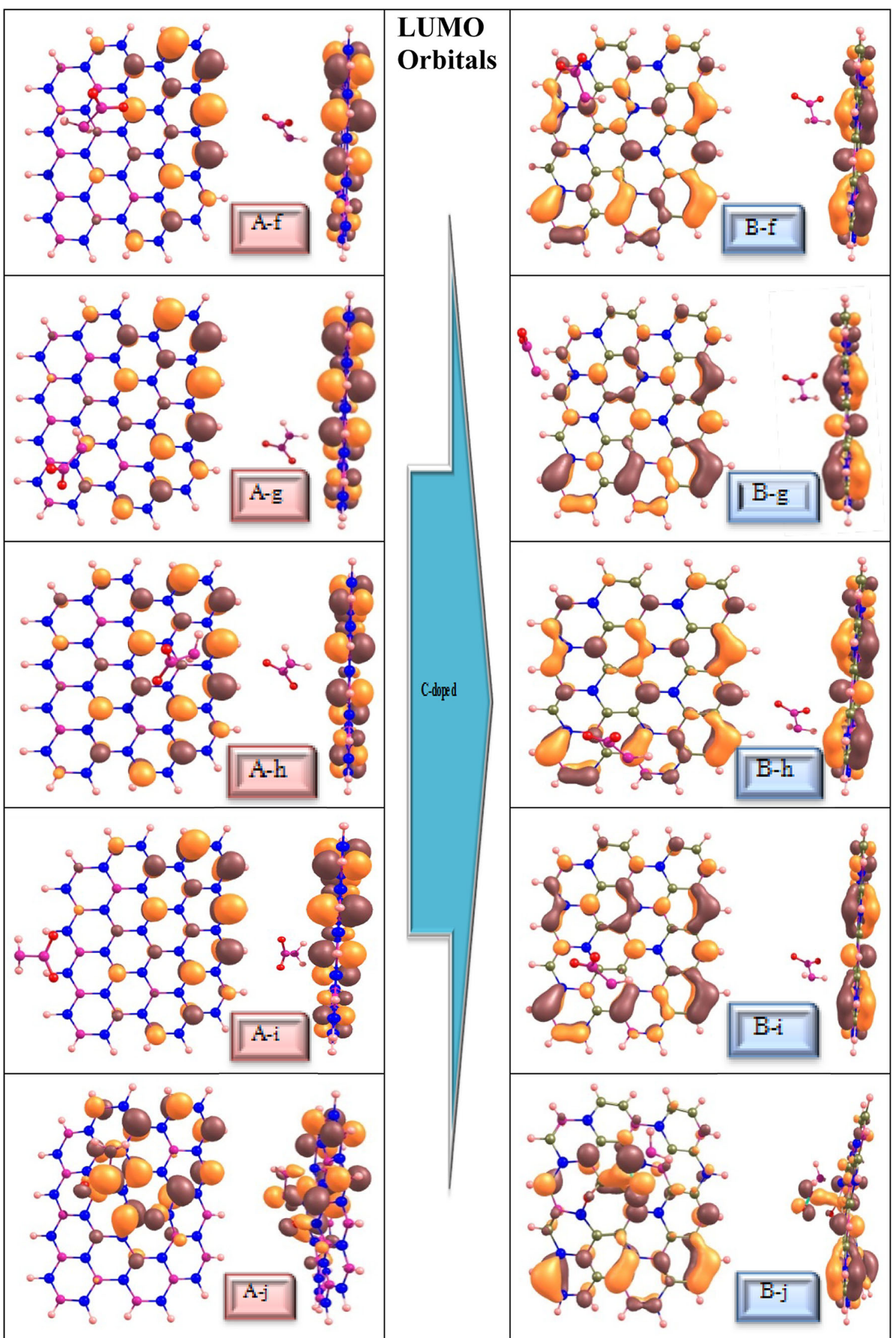

Fig. 3 continued 
Table 2 NBO and Mulliken charge of nitramide on the surface of the $\mathrm{BN}$ nanosheet for the A-a to B-j models, and the $\rho_{1}=0$ for pure $\mathrm{NH}_{2} \mathrm{NO}_{2}$

\section{Results and discussion}

\section{Structural and geometrical properties}

Herein, the A model of the BN nanosheet contains 24B, $24 \mathrm{~N}$ and $18 \mathrm{H}$ atoms (B24N24H18, see Fig. 1) and in the B model $24 \mathrm{C}$ atoms are superseded in the layers 1, 3, 5, 7 and 9 in spite of B and N sites of nanosheet (B12N12C24H18, see Fig. 1). From the optimized results, the $\mathrm{B}-\mathrm{N}$ bond length of the A model is $1.44 \AA$ and the bond lengths of $\mathrm{B}$ $\mathrm{N}, \mathrm{B}-\mathrm{C}, \mathrm{N}-\mathrm{C}$ and $\mathrm{C}-\mathrm{C}$ in the $\mathrm{B}$ model are $1.45,1.39,1.54$ and $1.38 \AA$, respectively (see Fig S1 in supplementary data).

As seen in Fig S2 in supplementary data, the B-N, B-C and $\mathrm{N}-\mathrm{C}$ bond lengths and the $\angle \mathrm{B}-\mathrm{C}-\mathrm{N}$ bond angle of the A-a to $\mathrm{B}-\mathrm{j}$ models after adsorbing $\mathrm{NH}_{2} \mathrm{NO}_{2}$ molecule change slightly from the unadorned models.

The optimized results display that in the B-e model, the $\mathrm{NH}_{2} \mathrm{NO}_{2}$ molecule dissociates to $\mathrm{NH}_{2}$ and $\mathrm{NO}_{2}$ parts, and in this form the $\mathrm{NH}_{2}$ part is adsorbed on the nanosurface and the $\mathrm{NO}_{2}$ part goes away from the nanosheet. In the A-j model, the $\mathrm{NH}_{2} \mathrm{NO}_{2}$ molecule dissociates into $2 \mathrm{O}$ atoms and $\mathrm{NNH}_{2}$ part, and also in this model the $2 \mathrm{O}$ atoms are chemically adsorbed on the surface of the nanosheet and the $\mathrm{NNH}_{2}$ part goes away from the nanosheet. Also in the B-j model, the $\mathrm{NH}_{2} \mathrm{NO}_{2}$ molecule dissociates into $\mathrm{NH}_{2}$, $\mathrm{NO}$ and $\mathrm{O}$ parts; the $\mathrm{O}$ atom is chemically connected on the surface of the nanosheet and other parts go away from the nanosheet. On the other hand, in the other adsorption models after optimizing the $\mathrm{NH}_{2} \mathrm{NO}_{2} / \mathrm{BN}$ nanosheet complex, the $\mathrm{NH}_{2} \mathrm{NO}_{2}$ molecule goes away from the nanosheet and so the type of adsorption process of these systems is physorption.

According to calculated results in Table 1, the average distance between the $\mathrm{NH}_{2} \mathrm{NO}_{2}$ molecule and the $\mathrm{BN}$ nanosheet in the B-e, A-j and B-j models is $1.51,1.77$ and $1.63 \AA$, respectively. By replacing $\mathrm{C}$ atoms, the geometrical structure of the $\mathrm{BN}$ nanosheet is dramatically deformed and so the average distance of the $\mathrm{NH}_{2} \mathrm{NO}_{2} /$ nanosheet decreases.

Comparison results show that the adsorption energy of the $\mathrm{B}-\mathrm{e}, \mathrm{A}-\mathrm{j}$ and $\mathrm{B}-\mathrm{j}$ models is positive due to dissociation of the $\mathrm{NH}_{2} \mathrm{NO}_{2}$ molecule on the surface of the nanosheet, whereas the $E_{\mathrm{ads}}$ values of the other models are negative and these adsorbed models are exothermic. Also, the B-g model with $E_{\text {ads }}=-10.48 \mathrm{kcal} / \mathrm{mol}$ is the most stable adsorption model (see Table 1). The obtained results demonstrate that the $E_{\text {ads }}$ of the $\mathrm{NH}_{2} \mathrm{NO}_{2}$ /nanosheet system depends on $\mathrm{C}$-replaced positions and $\mathrm{NH}_{2} \mathrm{NO}_{2}$ molecule orientation. The $\mathrm{C}$-replacing atoms increase the adsorption of the $\mathrm{NH}_{2} \mathrm{NO}_{2}$ molecule on the surface of the nanosheet. These results confirm that $\mathrm{C}$-replaced $\mathrm{BN}$ nanosheet is a good compound for adsorbing $\mathrm{NH}_{2} \mathrm{NO}_{2}$ molecule. In all studied models (the A-a to B-j models), the basis set superposition error (BSSE) is in the range $0.0005-0.001 \mathrm{kcal} / \mathrm{mol}$. In the A-a to B-j models, the binding energy $\left(E_{\mathrm{bin}}\right)$ values are negative and the $\mathrm{NH}_{2} \mathrm{NO}_{2}$ molecule is adsorbed on the surface of the $\mathrm{BN}$ nanosheet. The maximum binding energy is seen in the B-e, A-j and B-j models with $-173.22,-214.22$ and $-257.87 \mathrm{kcal} / \mathrm{mol}$, respectively.

To understand the deforming structures of the BN nanosheet and $\mathrm{NH}_{2} \mathrm{NO}_{2}$ molecule in the $\mathrm{BN}$ nanosheet/ $\mathrm{NH}_{2} \mathrm{NO}_{2}$ complex, the deformation energy of the $\mathrm{BN}$ nanosheet, $\mathrm{NH}_{2} \mathrm{NO}_{2}$ molecule and $\mathrm{BN}$ nanosheet $/ \mathrm{NH}_{2} \mathrm{NO}_{2}$ complex is calculated using Eqs. (2-4) and the results are listed in Table 1.

Comparisons of structural results indicate that significant curvature in the geometry of nanosheet and $\mathrm{NH}_{2} \mathrm{NO}_{2}$ molecule occurs in the B-e, A-j and B-j adsorption models. On the other hand, the deformation energy of the BN nanosheet $\left(E_{\mathrm{def}} \mathrm{BN}\right.$ nanosheet) for the B-a, B-b, B-c, B-d, B-f, B-g, B-h and B-i models is negative and for the A-a to A-j models positive. The negative value of deformation energy shows that the structures of $\mathrm{NH}_{2} \mathrm{NO}_{2}$ molecule and $\mathrm{BN}$ nanosheet are deformed spontaneously from the original state and all deformed structures are stable from the thermodynamic point of view. However, the deformation energies of the B-e, A-j and $\mathrm{B}-\mathrm{j}$ models for $\mathrm{NH}_{2} \mathrm{NO}_{2}$ molecule, $\mathrm{BN}$ nanosheet and $\mathrm{NH}_{2} \mathrm{NO}_{2} / \mathrm{BN}$ nanosheet complex are positive and so the deformation of these models is endothermic and needs more energy. The order 
Table 3 Calculated quantum parameters for adsorption of nitramide on the surface of the pristine and C-replaced $\mathrm{BN}$ nanosheet for the A-a to B-j models

\begin{tabular}{|c|c|c|c|c|c|c|c|c|c|c|}
\hline Properties/eV & A-a & $A-b$ & $A-c$ & A-d & A-e & B-a & B-b & B-c & B-d & B-e \\
\hline$E($ LUMO) & -1.36 & -1.22 & -1.26 & -1.47 & -1.52 & -2.78 & -2.80 & -2.86 & -2.78 & -3.17 \\
\hline$E(\mathrm{HOMO})$ & -6.38 & -6.41 & -6.49 & -6.31 & -6.34 & -4.01 & -4.01 & -4.05 & -4.01 & -4.11 \\
\hline$E$ (gap) & 5.02 & 5.19 & 5.23 & 4.83 & 4.82 & 1.23 & 1.21 & 1.19 & 1.23 & 0.94 \\
\hline$I$ & 6.38 & 6.41 & 6.49 & 6.31 & 6.34 & 4.01 & 4.01 & 4.05 & 4.01 & 4.11 \\
\hline$A$ & 1.36 & 1.22 & 1.26 & 1.47 & 1.52 & 2.78 & 2.80 & 2.86 & 2.78 & 3.17 \\
\hline$\mu$ & -3.87 & -3.81 & -3.87 & -3.89 & -3.93 & -3.39 & -3.40 & -3.45 & -3.39 & -3.64 \\
\hline$X$ & 3.87 & 3.81 & 3.87 & 3.89 & 3.93 & 3.39 & 3.40 & 3.45 & 3.39 & 3.64 \\
\hline$\eta$ & 2.51 & 2.59 & 2.61 & 2.41 & 2.41 & 0.61 & 0.60 & 0.59 & 0.61 & 0.47 \\
\hline$S /(\mathrm{eV})^{-1}$ & 0.20 & 0.19 & 0.19 & 0.20 & 0.20 & 0.81 & 0.82 & 0.84 & 0.81 & 1.06 \\
\hline$E_{\mathrm{FL}}$ & -3.87 & -3.81 & -3.87 & -3.89 & -3.93 & -3.39 & -3.40 & -3.45 & -3.39 & -3.64 \\
\hline$\Delta \Phi$ & -2.51 & -2.59 & -2.61 & -2.41 & -2.41 & -0.61 & -0.60 & -0.59 & -0.61 & -0.47 \\
\hline$\omega$ & 2.98 & 2.80 & 2.87 & 3.13 & 3.21 & 9.37 & 9.58 & 10.08 & 9.41 & 14.09 \\
\hline$\Delta N$ & -1.54 & -1.47 & -1.48 & -1.61 & -1.63 & -5.52 & -5.62 & -5.84 & -5.55 & -7.74 \\
\hline Properties/eV & A-f & A-g & A-h & A-i & $A-j$ & B-f & B-g & B-h & $\mathrm{B}-\mathrm{i}$ & $B-j$ \\
\hline$E(\mathrm{LUMO})$ & -1.38 & -1.39 & -1.33 & -1.45 & -1.85 & -2.80 & -2.87 & -2.77 & -2.76 & -2.87 \\
\hline$E(\mathrm{HOMO})$ & -6.38 & -6.48 & -6.53 & -6.35 & -5.91 & -4.02 & -4.03 & -4.01 & -4.00 & -4.20 \\
\hline$E$ (gap) & 5.00 & 5.09 & 5.20 & 4.90 & 4.06 & 1.22 & 1.16 & 1.24 & 1.24 & 1.33 \\
\hline$I$ & 6.38 & 6.48 & 6.53 & 6.35 & 5.91 & 4.02 & 4.03 & 4.01 & 4.00 & 4.20 \\
\hline$A$ & 1.38 & 1.39 & 1.33 & 1.45 & 1.85 & 2.80 & 2.87 & 2.77 & 2.76 & 2.87 \\
\hline$\mu$ & -3.88 & -3.93 & -3.93 & -3.90 & -3.88 & -3.41 & -3.45 & -3.39 & -3.38 & -3.53 \\
\hline$X$ & 3.88 & 3.93 & 3.93 & 3.90 & 3.88 & 3.41 & 3.45 & 3.39 & 3.38 & 3.53 \\
\hline$\eta$ & 2.50 & 2.54 & 2.60 & 2.45 & 2.03 & 0.61 & 0.58 & 0.62 & 0.62 & 0.66 \\
\hline$S /(\mathrm{eV})^{-1}$ & 0.19 & 0.19 & 0.19 & 0.20 & 0.24 & 0.81 & 0.86 & 0.80 & 0.80 & 0.75 \\
\hline$E_{\mathrm{FL}}$ & -3.88 & -3.93 & -3.93 & -3.90 & -3.88 & -3.41 & -3.45 & -3.39 & -3.38 & -3.53 \\
\hline$\Delta \Phi$ & -2.50 & -2.54 & -2.60 & -2.45 & -2.03 & -0.61 & -0.58 & -0.62 & -0.62 & -0.66 \\
\hline$\omega$ & 3.01 & 3.04 & 2.97 & 3.10 & 3.70 & 9.53 & 10.26 & 9.26 & 9.21 & 9.39 \\
\hline$\Delta N$ & 1.55 & -1.54 & -1.51 & -1.59 & -1.91 & -5.59 & -5.94 & -5.46 & -5.45 & -5.31 \\
\hline
\end{tabular}

of deformation energy in the B-e, A-j and B-j models is: $E_{\text {def }}(\mathrm{A}-\mathrm{j})>E_{\text {def }}(\mathrm{B}-\mathrm{j})>E_{\text {def }}(\mathrm{B}-\mathrm{e})$. Furthermore, the deformation energy of the $\mathrm{NH}_{2} \mathrm{NO}_{2}$ molecule and total deformation energy of the A-a, A-b, A-c, A-d, A-e, A-f, B-a, B-b, B-c, B-d and B-f models are negative. The total deformation energy of the $\mathrm{B}$ model is lower than that of the A models, thereby replacing of carbon atoms alter the structure of the $\mathrm{BN}$ nanosheet $/ \mathrm{NH}_{2} \mathrm{NO}_{2}$ complex.

Dipole moment is one another properties of system that it used to detect the nature of reactivity and impurity atoms effect of system. The dipole moment of the C-replaced models (B-a to B-j models) are more than pristine models (A-a to A-j models). The replacing carbon atoms increase dipole moment and reactivity of nanosheet (see Table 1), and also the orientations of $\mathrm{NH}_{2} \mathrm{NO}_{2}$ molecule on the surface of $\mathrm{BN}$ nanosheet change the dipole moment values. The dipole moment of A-g model (6.33 debye) and B-e model (13.84 debye) are significantly more than other those models. It is notable that with increasing the dipole moment at the A-a to B-j models the adsorption and interaction energy of system increase.

\section{Analysis HOMO and LUMO orbitals}

For understanding the structural and electrical properties of $\mathrm{BN}$ nanosheet/ $\mathrm{NH}_{2} \mathrm{NO}_{2}$ complex, the $\mathrm{HOMO}$ and the LUMO orbitals of the A-a to B-j models are determined and results are given in Fig. 3 .

The HOMO orbital density of the A-a, A-b, A-c, A-d, A-e, A-f, A-g, A-h and A-i models are uniformly localized surrounding $\mathrm{NH}_{2} \mathrm{NO}_{2}$ molecule, whereas at the A-j model the HOMO orbital density is localized around $\mathrm{NH}_{2} \mathrm{NO}_{2}$ molecule and near adsorption position of nanosheet. While with replacing $\mathrm{C}$ atoms in the $\mathrm{B}-\mathrm{a}, \mathrm{B}-\mathrm{b}, \mathrm{B}-\mathrm{c}, \mathrm{B}-\mathrm{d}, \mathrm{B}-\mathrm{e}, \mathrm{B}-\mathrm{f}$, $\mathrm{B}-\mathrm{g}, \mathrm{B}-\mathrm{h}$ and $\mathrm{B}-\mathrm{i}$ models the HOMO orbital density are distributed on the end layers surface of nanosheet, and also in the B-j model the HOMO orbital density is localized surrounding $\mathrm{NH}_{2} \mathrm{NO}_{2}$ and end layers of nanosheet. 

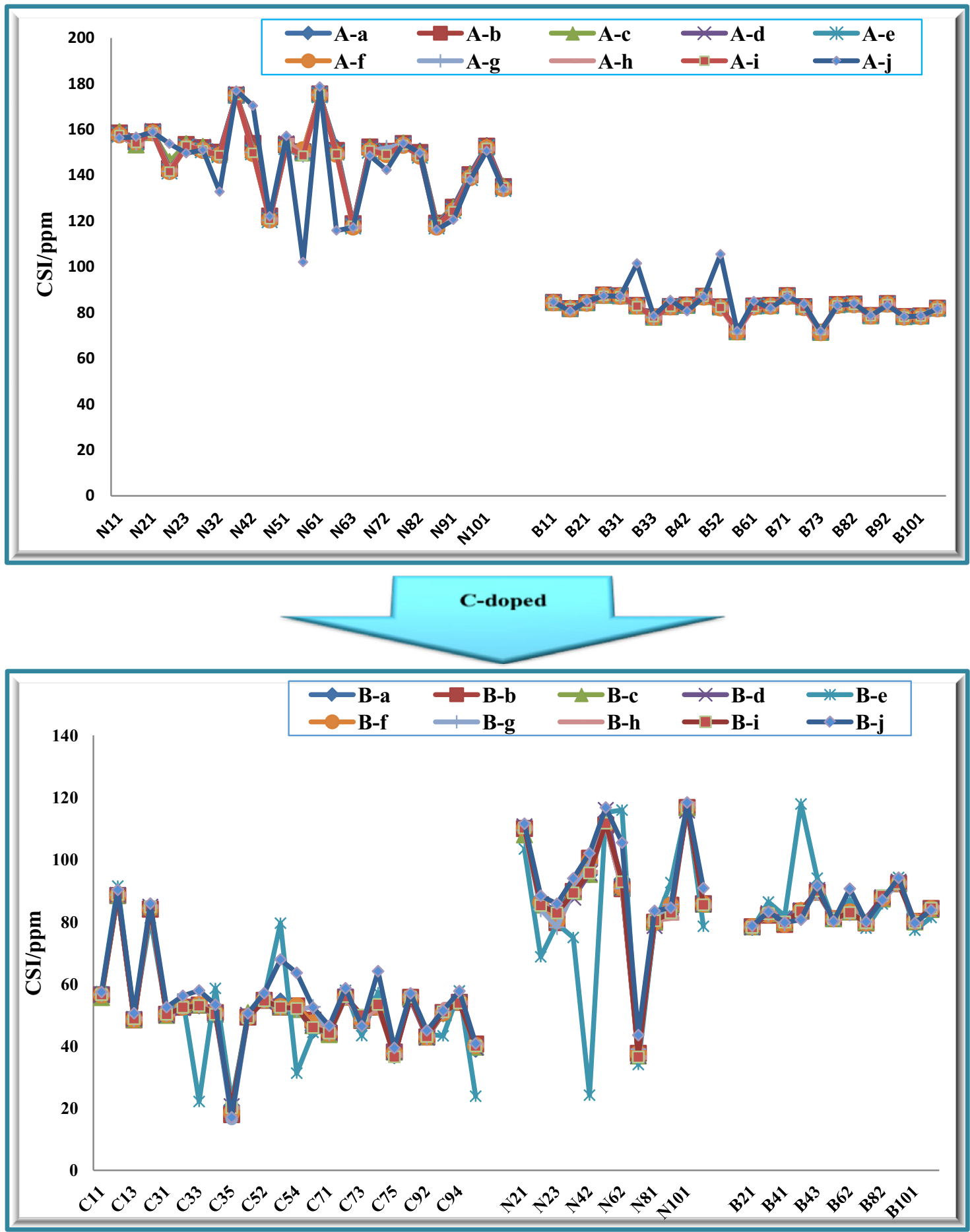

Fig. 4 The CSI plots for $\mathrm{NH}_{2} \mathrm{NO}_{2}$ adsorption on the surface of pristine and C-doped BN nanosheet (A-a to B-j models, see Fig. 2)

It is remarkable that the LUMO orbital densities at all adsorption models except A-j and B-j models are distributed uniformly around nanosheet. These results confirm that the surface of nanosheet is a good surface for electrophilic reaction. The negative values of $\Delta \rho\left(\Delta \rho=\rho_{2}-\rho_{1}\right)$ of NBO and Mulliken charge for $\mathrm{NH}_{2} \mathrm{NO}_{2}$ molecule confirm that the
$\mathrm{NH}_{2} \mathrm{NO}_{2}$ molecule is an electron acceptor and decrease the charge densities around nanosheet from original state (see Table 2).

The calculated gap energy $\left(E_{\mathrm{g}}\right)$ for the A-a to B-j models are tabulated in Table 3. The $E_{\mathrm{g}}$ energy of the A-a to A-j models is in range $4.06-5.23 \mathrm{eV}$; these results are in 
agreement with other research [32]. The $E_{\mathrm{g}}$ energy of the $\mathrm{B}-\mathrm{a}$ to $\mathrm{B}-\mathrm{j}$ models is in range $0.94-1.33 \mathrm{eV}$ and is lower than the A-a to A-j models. Due to replacing carbon atoms, the conductivity and reactivity of the B-a to B-j models are more than the A-a to A-j models, and also the B-a to B-j models are a good semiconductor in electronic applications.

The density of state (DOS) plots for the A-a to B-j adsorption models display that at the A-a, A-b, A-c, A-d, A-e, A-f, A-g and A-h models in the HOMO and LUMO regions there are 12 and 14 peaks, respectively (see Fig S3). In the B-a, B-b, B-c, B-d, B-f, B-g, B-h and B-i in the HOMO and LUMO region, there are 16 and 17 peaks, respectively. In the A-j, B-e and B-j models due to dissociation of $\mathrm{NH}_{2} \mathrm{NO}_{2}$ molecule in the HOMO and LUMO regions, we observe 18 and 19 peaks, respectively. Comparison results exhibit that in the LUMO region, more maxima peaks are observed than in the HOMO region.

By replacing $\mathrm{C}$ atoms, two small peaks are seen in the gap region and then due to these unfolded peaks the $E_{\mathrm{g}}$ values of the BN nanosheet decrease significantly compared to pristine BN nanosheet models. So, the conductivity of the C-replaced $\mathrm{BN}$ nanosheet is more than that of the pristine model of $\mathrm{BN}$ nanosheet.

According to the calculated quantum parameters of the BN nanosheet/ $\mathrm{NH}_{2} \mathrm{NO}_{2}$ in Table 3, the global hardness $(\eta)$ values of the A-a to A-j models and the B-a to B-j models are in the range $2.03-2.61$ and $0.47-0.66 \mathrm{eV}$, respectively. The global hardness of C-replaced BN nanosheet is lower than that of pristine $\mathrm{BN}$ nanosheet and so the reactivity of C-replaced $\mathrm{BN}$ nanosheet is more than that of pristine $\mathrm{BN}$ nanosheet. This fact confirms that the C-replaced BN nanosheet is more active than the pristine models for adsorbing and detecting $\mathrm{NH}_{2} \mathrm{NO}_{2}$ molecules.

The electrochemical potential $(\mu)$ results reveal that on replacing $\mathrm{C}$ atoms and adsorbing $\mathrm{NH}_{2} \mathrm{NO}_{2}$ molecules, the electrochemical potential of the system changes slightly from the original state.

The NBO and Milliken charge around the $\mathrm{NH}_{2} \mathrm{NO}_{2}$ molecule $\left(\Delta \rho_{\mathrm{NBO}}\right.$ and $\left.\Delta \rho_{\text {mulk }}\right)$ and the maximum amount of electronic charge $(\Delta N)$ for the A-a to B-j models are negative (see Tables 2, 3). The negative values of $\Delta \rho_{\mathrm{NBO}}$, $\Delta \rho_{\text {mulk }}$ and $\Delta \mathrm{N}$ at all adsorption models demonstrate that in the $\mathrm{BN}$ nanosheet/ $\mathrm{NH}_{2} \mathrm{NO}_{2}$ system, the $\mathrm{BN}$ nanosheet has a donor electron effect and $\mathrm{NH}_{2} \mathrm{NO}_{2}$ molecule has an acceptor electron effect. Due to this effect, the charge density is localized around the $\mathrm{NH}_{2} \mathrm{NO}_{2}$ molecule.

The work function $(\Delta \Phi)$ is the minimum energy to remove an electron from a solid surface to outside of the compound and it is used to describe the emitted electron current densities.

The work function values of the A-a to A-j models and the $\mathrm{B}-\mathrm{a}$ to $\mathrm{B}-\mathrm{j}$ models are in the range of -2.03 to
$-2.61 \mathrm{eV}$ and -0.47 to $-0.66 \mathrm{eV}$, respectively (see Table 3). A comparison of results shows that the work function of $\mathrm{C}$-replaced $\mathrm{BN}$ nanosheet $/ \mathrm{NH}_{2} \mathrm{NO}_{2}$ complex is lower than that of pristine models and so the emitted electron current densities of the B-a to B-j models are lower than those of the A-a to A-j models.

\section{Nuclear magnetic resonance parameters}

In this section, the evaluated nuclear magnetic resonance (NMR) parameters are used to understand the charge density of the material. The nuclear magnetic resonance parameters are generated by the response of electrons to an external uniform magnetic field and the spin-spin interaction. By using the gauge included atomic orbital (GIAO) approach [40-42], the chemical shielding isotropic (CSI) and chemical shielding anisotropic (CSA) parameters for ${ }^{11} \mathrm{~B},{ }^{15} \mathrm{~N}$ and ${ }^{13} \mathrm{C}$ sites are calculated using Eqs. $(15,16)$ :

$C S I=\frac{1}{3}\left(\sigma_{x x}+\sigma_{y y}+\sigma_{z z}\right)$

$\mathrm{CSA}=\sigma_{z z}-\frac{1}{2}\left(\sigma_{x x}+\sigma_{y y}\right) \quad \sigma_{z z}>\sigma_{y y}>\sigma_{x x}$.

The calculated CSI and CSA parameters of the A-a to B-j models are given in Tables S3-S6 in supplementary data. The NMR spectrum and the CSI plots for the A-a to B-j models are shown in Fig. 4 and Fig S4 in supplementary data. It is evident that the CSI values of $\mathrm{N}$ atoms are more than those of $\mathrm{C}$ and $\mathrm{B}$ atoms due to more electronegativity of the $\mathrm{N}$ atom with respect to $\mathrm{B}$ and $\mathrm{C}$ atoms. In the $\mathrm{A}-\mathrm{a}$ to B-j models, the CSI values of N42, N51, N61, B32, B52, C12, C14, C53, C72, C74, C91, C94, N61, N101 and B43 sites are more than those of other sites of the nanosheet, whereas the CSI values of N32, N43, N52, N62, N83, N52, B73, C13, C35, C54, C75, C95, N42 and N63 sites are lower than those of other sites of the nanosheet. Therefore, the electrostatic behavior of the BN nanosheet surface varies significantly from the unabsorbed system. Comparison NMR spectrum of the A-a to B-j models (see Fig S4) shows that the shielding parameters of the A-j, B-e and B-j models are different from those of other adsorption models due to dissociation of the $\mathrm{NH}_{2} \mathrm{NO}_{2}$ molecule.

\section{The natural bond orbital (NBO)}

The natural bonding orbital (NBO) is one of the important parameters used to understand the effects of $\mathrm{NH}_{2} \mathrm{NO}_{2}$ adsorption on the structural and orbital properties of the nanosheet. Using the natural bonding orbital results, the interaction energy or second-order perturbation interaction energy $E^{(2)}$ [44] between the bond orbitals with antibond orbitals or Rydberg orbitals can be calculated with delocalization $i \rightarrow j$ : 
$E^{(2)}=q_{i} \frac{F_{i j}^{2}}{\varepsilon_{j}-\varepsilon_{i}}$,

where $F_{i j}$ and $q_{i}$ are off-diagonal and donor orbital occupancy, respectively, and $\varepsilon_{i}$ and $\varepsilon_{j}$ are orbital energies. According to the NBO calculated results of Tables S7-S10 in supplementary data, the $E^{(2)}$ values of the A-a to A-j models are greater than those of $\mathrm{B}-\mathrm{a}$ to $\mathrm{B}-\mathrm{j}$ models. This result confirms that the stabilization energy between the donor and acceptor orbitals in the C-replaced BN nanosheet is significantly lower than that of the pristine models. Thereby by replacing $\mathrm{C}$ atoms, the activities and polarizability of the BN nanosheet increases significantly from the original state.

A comparison of the NBO results shows that the highest stabilization energy $\left(E^{(2)}\right)$ in the A-a, A-b, A-c, A-d, A-e models is shown at transition between the donor orbital to acceptor orbital $\sigma B 62-N 52 \rightarrow \sigma^{*} B 52-N 52$ and for the A-f, A-g, A-h, A-i and A-j models at the transition between the donor orbital and acceptor orbital $\sigma B 62-N 52 \rightarrow$ $\sigma^{*} B 52-N 52$. On the other hand, the highest stabilization energy $\left(E^{(2)}\right)$ in the B-a to B-j models is shown at the transition between the donor orbital and acceptor orbital $\sigma C 53-B 42 \rightarrow \sigma^{*} C 54-C 53$.

\section{Molecular electrostatic potential}

The molecular electrostatic potential (MEP) calculated results are used to determine the size and shape, and the positive, negative and neutral regions of the molecule $[45,46]$. These results are useful for determining the charge distribution around the compound surface and nucleophilic or electrophilic region of the compound. This means that for all A-a to B-j models, the MEP and contour potential plots are calculated around the adsorption position and all calculated results are shown in Fig S5 in supplementary data. Herein, the green and red colors represent the negative and positive charges or the electrophilic and nucleophilic regions, respectively. The calculated results point out in all A-a to B-j models a negative potential, green color, is shown around the $\mathrm{NH}_{2} \mathrm{NO}_{2}$ molecule, whereas a positive potential, red color, is localized around the BN nanosheet. These results are completely in agreement with the NBO, quantum and NMR results. Therefore in the A-a to B-e models, due to donor electron effect of the $\mathrm{BN}$ nanosheet, a low charge transfer occurs between the nanosheet and the $\mathrm{NH}_{2} \mathrm{NO}_{2}$ molecule. Comparison of MEP and contour potential plots of the A and B models demonstrate that with C-replacing atoms the charge transfer between the $\mathrm{BN}$ nanosheet and $\mathrm{NH}_{2} \mathrm{NO}_{2}$ decreases slightly compared with the pristine models.

\section{Conclusions}

In this work, we investigated the structural, physical and electrical properties of adsorption $\mathrm{NH}_{2} \mathrm{NO}_{2}$ molecule on the surface of the pristine and C-replaced BN nanosheet. In the A-a to B-j models, the adsorption energy of the $\mathrm{NH}_{2}$ $\mathrm{NO}_{2} / \mathrm{BN}$ nanosheet system strongly depends on the adsorption orientation of the $\mathrm{NH}_{2} \mathrm{NO}_{2}$ molecule and C-replaced atoms. The adsorption energy of $\mathrm{NH}_{2} \mathrm{NO}_{2}$ molecule on the outer surface of the pristine and C-replaced $\mathrm{BN}$ nanosheet is negative, exothermic and favorable.

The $E_{\mathrm{g}}, \mathrm{NBO}$ and global hardness results of C-replaced BN nanosheet are lower than those of the pristine models, and so the conductivity, polarizability and activity of $\mathrm{C}$-replaced BN nanosheets are greater than those of pristine BN nanosheets. These results demonstrate that the C-replaced BN nanosheet models are good compounds to act as sensitive sensors and absorbers of the $\mathrm{NH}_{2} \mathrm{NO}_{2}$ molecule.

Acknowledgements The authors thank the Computational Information Center of Malayer University for providing the necessary facilities to carry out the research.

Open Access This article is distributed under the terms of the Creative Commons Attribution 4.0 International License (http://crea tivecommons.org/licenses/by/4.0/), which permits unrestricted use, distribution, and reproduction in any medium, provided you give appropriate credit to the original author(s) and the source, provide a link to the Creative Commons license, and indicate if changes were made.

\section{References}

1. Novoselov, K.S., Geim, A.K., Morozov, S.V., Jiang, D., Zhang, Y., Dubonos, S.V., Grigorieva, I.V., Firsov, A.A.: Electric field effect in atomically thin carbon films. Science 306, 666-669 (2004)

2. Geim, A.K., Novoselov, K.S.: The rise of graphene. Nat. Mater. 6, 183-191 (2007)

3. Zhang, Y.B., Tan, Y.W., Stormer, H.L., Kim, P.: Experimental observation of the quantum Hall effect and Berry's phase in graphene. Nature 438, 201-204 (2005)

4. Morozov, S.V., Novoselov, K.S., Katsnelson, M.I., Schedin, F., Elias, D.C., Jaszczak, J.A., Geim, A.K.: Giant intrinsic carrier mobilities in graphene and its bilayer. Phys. Rev. Lett. 100, 016602-016604 (2008)

5. Novoselov, K.S., Jiang, Z., Zhang, Y., Morozov, S.V., Stormer, H., Zeitler, U., Maan, J.C., Boebinger, G.S., Kim, P., Geim, A.K.: Room-temperature quantum Hall effect in graphene. Science 315, 1379 (2007)

6. Zhou, J., Wang, Q., Sun, Q., Jena, P.: Stability and electronic structure of bilayer graphone. Appl. Phys. Lett. 98, 063108-5 (2011)

7. Pujari, B.S., Kanhere, D.G.: Density functional investigations of defect-induced mid-gap states in graphane. J. Phys. Chem. C 113, 21063-21067 (2009)

8. Lu, G., Ocula, E.L., Chen, J.: Gas detection using low-temperature reduced graphene oxide sheets. Appl. Phys. Lett. 94, 083111-083113 (2009) 
9. Pashangpour, M., Bagheri, Z., Ghaffari, V.: A comparison of electronic transport properties of graphene with hexagonal boron nitride substrate and graphene, a first principle study. Eur. Phys. J. B 86(269), 1-6 (2013)

10. Robinson, J.T., Perkins, F.K., Snow, E.S., Wei, Z.Q., Sheehan, P.E.: $\mathrm{NO}_{2}$ and humidity sensing characteristics of few-layer graphene. Nano Lett. 8, 3137-3140 (2008)

11. Yoon, H.J., Jun, D.H., Yang, J.H., Zhou, Z., Yang, S.S., Cheng, M.M.: Carbon dioxide gas sensor using a graphene sheet. Sens. Actuators B. Chem. 157, 310-331 (2011)

12. Sakhavand, N., Shahsavari, R.: Synergistic behavior of tubes, junctions, and sheets imparts mechano-mutable functionality in 3D porous boron nitride nanostructures. J. Phys. Chem. C 118(39), 22730-22738 (2014)

13. Zhou, J., Wang, Q., Sun, Q., Jena, P.: Stability and electronic structure of bilayer graphone. Appl. Phys. Lett. 98, 063108/1-3 (2011)

14. Ahin, H., Ataca, C., Ciraci, S.: Magnetization of graphane by dehydrogenation. Appl. Phys. Lett. 95, 222510/1-4 (2009)

15. Boukhvalov, D.W., Katsnelson, M.I., Lichtenstein, A.I.: Hydrogen on graphene: Electronic structure, total energy, structural distortions and magnetism from first-principles calculations. Phys. Rev. B 77, 035427/1-3 (2008)

16. Nair, R.R., Ren, W., Jalil, R., Riaz, I., Kravets, V.G., Britnell, L., Blake, P., Schedin, F., Mayorov, A.S., Yuan, S., Katsnelson, M.I., Cheng, H.M., Strupinski, W., Bulusheva, L.G., Okotrub, A.V., Grigorieva, I.V., Grigorenko, A.N., Novoselov, K.S., Geim, A.K.: Fluorographene: a two-dimensional counterpart of teflon. Small 6, 2877-2884 (2010)

17. Ahin, H., Topsakal, M., Ciraci, S.: Structures of fluorinated graphene and their signatures. Phys. Rev. B. 83, 115432-115438 (2011)

18. Withers, F., Dubois, M., Savchenko, A.K.: Electron properties of fluorinated single-layer graphene transistors. Phys. Rev. B. 82, 073403/1-6 (2010)

19. Li, J., Jin, P., Dai, W., Wang, C., Li, R., Wu, T., Tang, C.: Excellent performance for water purification achieved by activated porous boron nitride nanosheets. Math. Chem. Phys. 196, 186-193 (2017)

20. Li, J., Jin, P., Tang, C.: Cr(III) adsorption by fluorinated activated boron nitride: a combined experimental and theoretical investigation. RSC. Adv. 4, 14815-14821 (2014)

21. Park, C.H., Louie, S.G.: Energy gaps and Stark effect in boron nitride nanoribbons. Nano Lett. 8, 2200-2203 (2008)

22. Zhang, Z., Guo, W.: Energy-gap modulation of BN ribbons by transverse electric fields: first-principles calculations. Phys. Rev. B. 77, 075403-075405 (2008)

23. Sun, L., Li, Y., Li, Z., Li, Q., Zhou, Z., Chen, Z., Yang, Z., Hou, J.G.: Electronic structures of $\mathrm{SiC}$ nanoribbons. J. Chem. Phys. 129, 174114/1-15 (2008)

24. Botello-Méndez, A.R., Lpez-Ur, F., Terrones, M., Terrones, H.: Magnetic behavior in zinc oxide zigzag nanoribbons. Nano Lett. 8, 1562-1565 (2008)

25. Li, H., Dai, J., Li, J., Zhang, S., Zhou, J., Zhang, L., Chu, W., Chen, D., Zhao, H., Yang, J., Wu, Z.: Electronic structures and magnetic properties of $\mathrm{GaN}$ sheets and nanoribbons. J. Phys. Chem. C 114, 11390-11395 (2010)

26. Zhang, X., Liu, Z., Hark, S.: Synthesis and optical characterization of single-crystalline AlN nanosheets. Solid. Stat. Commun. 143, 317-320 (2007)

27. Lopez, A., Bezanilla, H.J., Terrones, H., Sumpter, B.H.: Electronic structure calculations on edge functionalised armchair boron nitride nanoribbons. J. Phys. Chem. C 116(29), 15675-15681 (2012)

28. Anota, E.C., Juarez, A.R., Castro, M., Cocoletzi, H.H.: A density functional theory analysis for adsorption of the amine group on graphene and BN nanosheets. J. Mol. Model. 19, 321-328 (2013)

29. Barsan, N., Koziej, D., Weimar, U.: Metal oxide-based gas sensor research: how to? Sci. Direct. 121(1), 18-35 (2007)

30. Lin, Y.M., Valdes, G.A., Han, S.J., Farmer, D.B., Meric, I., Sun, Y., Wu, Y., Dimitrakopoulos, C., Grill, A., Avouris, P., Jenkins, K.A.: $100-\mathrm{GHz}$ transistors from Wafer-scale epitaxial graphene. Science 332, 1294-1297 (2010)

31. Zhao, J.Y., Zhao, F.Q., Ju, X.H., Gao, H.X., Zhou, S.Q.: Density functional theory studies on the adsorption of $\mathrm{NH}_{2} \mathrm{NO}_{2}$ on Al13 cluster. J. Clust. Sci. 23, 395-410 (2012)

32. Bhattacharya, A., Bhattacharya, S., Das, G.P.: Band gap functionalization of BN sheet. Phys. Rev. B. 85, 035415 (2012)

33. Zhang, Z., Guo, W., Dai, Y.: Stability and electronic properties of small boron nitride nanotubes. J. Appl. Phys. 105, 084312/1-8 (2009)

34. Zheng, F., Zhou, G., Liu, Z., Wu, J., Duan, W., Gu, B.L., Zhang, S.B.: Half metallicity along the edges of zigzag boron nitride nanoribbons. Phys. Rev. B. 78, 205415/1-4 (2008)

35. Neek-Amal, M., Beheshtian, J., Sadeghi, A., Michel, K.H., Peeters, F.M.: Boron nitride monolayer: a strain tunable nanosensor. J. Phys. Chem. C 117(25), 13261-13267 (2013)

36. Li, Y., Zhou, Z., Zhao, J.: Functionalization of BN nanotubes with dichlorocarbenes. Nanotechnology 19, 015202 (2008)

37. Wang, L., Yi, C., Zou, H., Xu, J., Xu, W.: On the isomerization and dissociation of nitramide encapsulated inside an armchair $(5,5)$ single-walled carbon nanotube. Mater. Chem. Phys. 127, 232-238 (2011)

38. Zhang, M.L., Ning, T., Zhang, S.Y., Li, Z.M., Yuan, Z.H., Cao, Q.X.: Response time and mechanism of Pd modified $\mathrm{TiO}_{2}$ gas sensor. Mater. Sci. Semi. Proc. 17, 149-154 (2014)

39. Schmidt, M.W., Baldridge, K.K., Boatz, J.A., Elbert, S.T., Gordon, M.S., Jensen, J.H., Koseki, S., Matsunaga, N., Nguyen, K.A., Su, S.J., Windus, T.L., Dupuis, M., Montgomery, J.A.: General atomic and molecular electronic structure system. J. Comp. Chem. 14, 1347-1363 (1993)

40. Rezaei-Sameti, M., Yaghoobi, S.: Theoretical study of adsorption of $\mathrm{CO}$ gas on pristine and AsGa-doped $(4,4)$ armchair models of BPNTs. Comput. Cond. Mater. 3, 21-29 (2015)

41. Rezaei Sameti, M.: The effect of doping three Al and N atoms on the chemical shielding tensor parameters of the boron phosphide nanotubes: a DFT study. Phys. B 407, 22-26 (2012)

42. Rezaei-Sameti, M., Samadi Jamil, E.: The adsorption of CO molecule on pristine, As, B, BAs doped $(4,4)$ armchair AlNNTs: a computational study. J. Nanostr. Chem. 3, 1-9 (2016)

43. James, C., Amalraj, A., Reghunathan, R., Hubert Joe, I., Jaya Kumar, V.S.: Structural conformation and vibrational spectroscopic studies of 2, 6-bis (p- $N, N$-dimethyl benzylidene) cyclohexanone using density functional theory. J. Raman Spect. 37, 1381-1392 (2006)

44. Glendening, E., Reed, A., Carpenter, J., Weinhold, F.: NBO Version 31. GaussianInc., Pittsburg (2003)

45. Bulat, F.A., Toro-Labbé, A., Brinck, T., Murray, J.S., Politzer, P.: Quantitative analysis of molecular surfaces: areas, volumes, electrostatic potentials and average local ionization energies. J. Mol. Model. 16(11), 1679-1691 (2010)

46. Bulat, F.A., Burgess, J.S., Matis, B.R., Baldwin, J.W., Macaveiu, L., Murray, J.S., Politzer, P.: Hydrogenation and fluorination of graphene models: analysis via the average local ionization energy. J. Phys. Chem. A 116(33), 8644-8652 (2012) 